\title{
Deer herbivory reduces web-building spider abundance by simplifying forest vegetation structure
}

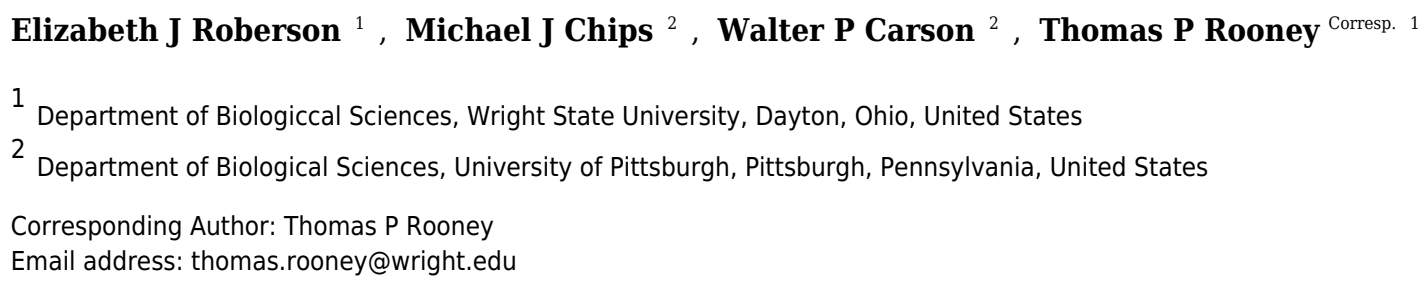

Indirect ecological effects are a common feature of ecological systems, arising when one species affects interactions among two or more other species. We examined how browsing by white-tailed deer (Odocoileus virginianus) indirectly affected the abundance and composition of a web-building spider guild through their effects on the structure of the ground and shrub layers of northern hardwood forests. We examined paired plots consisting of deer-free and control plots in the Allegheny Plateau region Pennsylvania and Northern Highlands region of Wisconsin. We recorded the abundance of seven types of webs, each corresponding to a family of web-building spiders. We quantified vegetation structure and habitat suitability for the spiders by computing a web scaffold availability index (WSAl) at $0.5 \mathrm{~m}$ and $1.0 \mathrm{~m}$ above the ground. At Northern Highlands sites, we recorded prey availability. Spider webs were twice as abundant in deer-free plots compared to control plots, while WSAI was 7-12 times greater in deerfree plots. Prey availability was lower in deer-free plots. With the exception of funnel web-builders, all spider web types were significantly more abundant in deer-free plots. Both deer exclusion and the geographic region of plots were significant predictors of spider community structure. In closed canopy forests with high browsing pressure, the low density of tree saplings and shrubs provides few locations for web-building spiders to anchor webs. Recruitment of these spiders may become coupled with forest disturbance events that increase tree and shrub recruitment. By modifying habitat structure, deer appear to indirectly modify arthropod food web interactions. As deer populations have increased in eastern North America over the past several decades, the effects of deer on web-building spiders may be widespread. 
1 Deer herbivory reduces web-building spider abundance by simplifying forest vegetation structure 2

4 Elizabeth J. Roberson ${ }^{1}$, Michael J. Chips ${ }^{2}$, Walter P. Carson ${ }^{2}$, Thomas P. Rooney ${ }^{1}$

5

61 Department of Biological Sciences, Wright State University, 3640 Colonel Glenn Hwy.,

7 Dayton $\mathrm{OH} 45435$, USA

82 Department of Biological Sciences, University of Pittsburgh, A234 Langley Hall, Pittsburgh,

9 PA 15260, USA

10

11 Corresponding Author:

12 Rooney, Thomas P.

13 Department of Biological Sciences, Wright State University, 3640 Colonel Glenn Hwy., Dayton

$14 \mathrm{OH} 45435, \mathrm{USA}$

15 thomas.rooney@wright.edu 


\section{ABSTRACT}

18 Indirect ecological effects are a common feature of ecological systems, arising when one

19 species affects interactions among two or more other species. We examined how browsing by

20 white-tailed deer (Odocoileus virginianus) indirectly affected the abundance and composition of

21 a web-building spider guild through their effects on the structure of the ground and shrub layers

22 of northern hardwood forests. We examined paired plots consisting of deer-free and control plots

23 in the Allegheny Plateau region Pennsylvania and Northern Highlands region of Wisconsin. We

24 recorded the abundance of seven types of webs, each corresponding to a family of web-building

25 spiders. We quantified vegetation structure and habitat suitability for the spiders by computing a

26 web scaffold availability index (WSAI) at $0.5 \mathrm{~m}$ and $1.0 \mathrm{~m}$ above the ground. At Northern

27 Highlands sites, we recorded prey availability. Spider webs were twice as abundant in deer-free

28 plots compared to control plots, while WSAI was 7-12 times greater in deer-free plots. Prey

29 availability was lower in deer-free plots. With the exception of funnel web-builders, all spider

30 web types were significantly more abundant in deer-free plots. Both deer exclusion and the

31 geographic region of plots were significant predictors of spider community structure. In closed

32 canopy forests with high browsing pressure, the low density of tree saplings and shrubs provides

33 few locations for web-building spiders to anchor webs. Recruitment of these spiders may become

34 coupled with forest disturbance events that increase tree and shrub recruitment. By modifying

35 habitat structure, deer appear to indirectly modify arthropod food web interactions. As deer

36 populations have increased in eastern North America over the past several decades, the effects of

37 deer on web-building spiders may be widespread. 


\section{INTRODUCTION}

0

1

Indirect ecological effects due to direct interaction between two species that affect a third species (Wootton 1994) often arise due to the actions of dominant species, keystone species, or ecosystem engineers (Jones et al. 1994; Pringle 2008). Menge (1995) reported that indirect interactions account for $\sim 40 \%$ of the change in the abundance and percent cover of species after experimental manipulations of rocky intertidal food webs. These indirect effects occurred coincident with or shortly after direct effects were observed (Menge 1997). Despite their importance, indirect effects can be difficult to detect, particularly in short-term studies (Hamilton 2000). Moreover, indirect effects can be conflated with direct effects and therefore overlooked entirely (Wootton 1994). Here, we examine the indirect effects of a large mammalian generalist herbivore on the structure of a web-building spider guild.

White-tailed deer (Odocoileus virginianus, hereafter deer) in North America have increased in abundance in recent decades (Crête 1999; Ripple et al. 2010; Bressette et al. 2012). In the early 20th century, deer were rare or absent from most of the United States (Leopold et al. 1947). Now, high deer abundance presents several management problems in much of the United States (Warren 1997; Côté et al. 2004), including much of Wisconsin and Pennsylvania. Through selective feeding, deer directly affect forest communities by altering species composition and vegetation structure (Côté et al. 2004; Takatsuki 2009; Habeck and Schultz 2016). These direct effects have the potential to indirectly alter the abundance of co-occurring animal species (Rooney 2001; Rooney and Waller 2003; Sakai et al. 2012). For example, through resource competition, deer can negatively affect the abundance of small granivorous mammals. McShea (2000) observed that in years of low food (acorn) abundance, deer reduced the abundance of two 
62 common species of rodent by 50\%. Similarly, elk (Cervus elaphus) reduced vegetation cover,

63 thereby causing a decline in the abundance of woodrats, voles, and two species of mice (Parsons

64 et al. 2013). Additionally, deer herbivory can alter resource quality for other herbivores by

65 altering plant species composition, or increasing secondary metabolites of particular species

66 (Vourc'h et al. 2001; Nuttle et al. 2011). A reduction in vegetation cover and vertical complexity

67 alters habitat for birds and other flying species (Rooney 2001). The removal of deer can lead to

68 increased vertical structure and ground cover (Rooney 2009). In studies where deer are removed,

69 ground and shrub-nesting birds increase in abundance (McShea and Rappole 2000; Holt et al.

70 2011).

The indirect effect of deer on arthropods may be strong for species that depend on vegetation for habitat (Stewart 2001), because deer browsing reduces the three dimensional structure of the ground and shrub layers of forest habitats (Habeck and Schultz 2015). Vegetation structure is important for web-building spiders, which use woody and herbaceous surfaces as anchoring points for their webs. These anchoring points can be a limiting resource for web builders (Rypstra 1983; Uetz 1991; Gómez et al. 2016). Miyashita et al. (2004) examined this relationship in forested regions of Japan. They report that the abundance and richness of webbuilding spiders increased in areas without deer browsing. They attributed this to an increase in vegetation cover, or more specifically, physical structures for anchoring webs. In a follow-up study, Takada et al. (2008) found that web-building spiders were more vulnerable than non-web

81 builders to deer browsing. their habitat structure. We built on previous work (Miyashita et al. 2004; Takada et al. 2008) by identifying responses of a broader range of web-building spiders to browsing effects. We 
85 examined web-building spider assemblages with and without deer, using a paired exclosure-

86 control design. We surveyed webs, documented vegetation structure, and inventoried spider prey

87 to determine the degree to which deer alter the abundance and composition of a web-building

88 spider guild, their habitat structure, and their prey abundance.

\section{MATERIALS AND METHODS}

Field Methods

We surveyed ten paired exclosure-control study plots located in the north-central and northeastern United States. Four paired plots were located in the Northern Highlands region of northern Wisconsin in Vilas County $\left(46^{\circ} 9^{\prime} \mathrm{N}, 89^{\circ} 51^{\prime} \mathrm{W}\right)$ on a 2500 ha property owned by Dairymen's Inc (Rooney 2009). This site supported high densities of deer throughout most of the

97 20th century, greatly altering plant community composition (Rooney 2009; Begley-Miller et al. 2014). In 1990, four deer exclosures were constructed in a 5 ha, old-growth hemlock-hardwood stand (predominantly Tsuga canadensis, Acer saccharum, and Betula alleghaniensis). Exclosures are $1.8-\mathrm{m}$ tall, constructed of wire mesh, and range in size from $169 \mathrm{~m}^{2}$ to $720 \mathrm{~m}^{2}$. Each exclosure has an adjacent control plot of the same area, but with ambient browsing pressure. The exclosures are separated from one another by a mean distance of $195 \pm 15 \mathrm{~m}$ (Rooney 2009). The remaining six paired plots were located in the Allegheny Plateau region in north-central

104 Pennsylvania in Elk County (41 $25^{\prime}$ N, $78^{\circ} 50^{\prime}$ W). In the early 2000s, the Pennsylvania Game

105 Commission constructed and maintained an array of six deer exclosures in State Gamelands 44 and 28 across a $200-\mathrm{km}^{2}$ area. This forest is part of the Hemlock-Northern Hardwood Association (Whitney 1990), and is composed of second and third growth forests (predominantly 
108 Acer rubrum, Prunus serotina, and Acer saccharum). For a more detailed description of the

109 region, see Horsley et al. (2003) and Chips et al. (2015). All exclosures were approximately

$1102.25-\mathrm{m}$ tall, ranged in size from $500 \mathrm{~m}^{2}$ to $900 \mathrm{~m}^{2}$, and had an adjacent control plot in a randomly

111 selected location within $20 \mathrm{~m}$ of the edge of each fence.

112 We surveyed our plots for spider webs, and classified spider webs according to their

113 structure (Fig. 1). Spider families can often be identified by the types of webs they build. We did

114 not always identify the spider that created the web because they were not always present.

115 However, we identified the putative family of spider that created each type of web we tallied

116 (Bradley 2013). We classified webs as: funnel web (Agelenidae), (b) sheet web (Linyphiidae),

117 (c) mesh web (Dictynidae), (d) reduced orb web (Uloboridae), (e) vertical orb web (Aranaeidae),

118 (f) tangle web (Theridiidae), (g) horizontal orb web (Tetragnathidae).

119 In the Northern Highlands region, we sampled spider webs in each paired exclosure and

120 control plot for five days each month in June, July, and August 2013. Each sampling day, we

121 divided each control and each exclosure plot into a $2 \times 2$ grid of four equal sections. For each

122 section, we randomly assigned a sampling distance (at least $1 \mathrm{~m}$ distance to the next section) and

123 angle $\left(0-90^{\circ}\right)$ using a random number generator. At the random point, we established a

124 cylindrical sampling area with a $0.5 \mathrm{~m}$ radius and a $2 \mathrm{~m}$ height. We used a spray mist bottle to fill

125 the entire area with water. This increased the visibility of all webs. We identified all spiders to

126 family based on web architecture (Fig. 1).

127 In the Allegheny Plateau region, we sampled spider webs in each exclosure and control

128 plot once in mid-July and once again mid-August of 2012 using a stratified random approach.

129 We sampled a $20 \mathrm{~m} \times 20 \mathrm{~m}$ area within each plot and divided each area into four $10 \mathrm{~m} \times 10 \mathrm{~m}$

130 sections. Within each section, we assigned Cartesian coordinates using a random number 
131 generator to determine the sample location, and a new location was generated for each sampling

132 date. At each location, we counted spider webs using the protocol described above. We identified

133 all spiders to family based on web architecture and recorded whether a spider was found in the

134 web.

135 After we counted and classified webs, we quantified vegetation structure and estimated

136 habitat suitability for web-building spiders using the Web Scaffold Availability Index (WSAI)

137 developed by Miyashita et al. (2004). In natural environments, vegetation provides most of the

138 supports for webs (Uetz 1991). The WSAI quantifies the structural complexity of vegetation. At

139 the center of the same random point used to sample spiders, we horizontally rotated a $1 \mathrm{~m}$ stick

140 at $0.5 \mathrm{~m}$ and $1 \mathrm{~m}$ above the ground. We recorded the number of times each web-anchoring

141 structure (branch, twig, leaf, log) touched the stick. The total number of recorded anchoring

142 points at $0.5 \mathrm{~m}$ and $1.0 \mathrm{~m}$ are recorded as the WSAI $0.5 \mathrm{~m}$ and WSAI $1.0 \mathrm{~m}$ (Miyashita et al.

143 2004).

144 At the Northern Highlands site only, we also examined prey availability to web-building

145 spiders using sticky traps. The traps were $23 \times 33-\mathrm{cm}$ sheets of clear plastic coated with Tangle

146 Trap Sticky Coating Aerosol (Tanglefoot Company, Grand Rapids, Michigan). Traps were

147 attached to 1-m high wooden poles. We deployed one sticky trap in each of the established

148 sections within the $2 \times 2$ grid using the same randomization method outlined above. We set up

149 the traps 24 hours before the first web sampling day; they were deployed for 5 days each

150 sampling month, after which they were covered with clear plastic wrap and placed on ice. In the

151 lab we counted all insects captured, and measured the body length of each insect specimen to the

152 nearest $\mathrm{mm}$.

153 
We examined the effect of deer on habitat suitability for web-building spiders by comparing WSAI values at $0.5 \mathrm{~m}$ and $1.0 \mathrm{~m}$ above the forest floor inside and outside of exclosures. Because our sampling intensity was greater in the Northern Highlands, we divided the abundance of spider webs by 7.5 to standardize effort (15 days/2 days). We first used twoway nested ANOVAs to determine if study-site location (Northern Highlands or Allegheny Plateau), the deer exclusion treatment, or the 4 subsamples per plot were significant sources of variation in explaining (a) WSAI at $0.5 \mathrm{~m}$ and (b) WSAI at $1.0 \mathrm{~m}$. For both WSAI heights, only the deer exclusion treatment was a significant source of variation. We therefore summed values from subsamples into a single value for each plot. We then used an independent two-sample ttest to examine differences in WSAI between exclosure and control plots. We conducted two tests, one for WSAI at $0.5 \mathrm{~m}$, and one test for WSAI at $1.0 \mathrm{~m}$. WSAI values were natural $\log$ transformed prior to analysis to meet assumptions of normality. multiple regression. We constructed a preliminary model using WSAI at $0.5 \mathrm{~m}$, and WSAI at 1.0 $\mathrm{m}$ as independent variables, and spider web abundance as the dependent variable. We performed stepwise regression with backwards elimination, and used the Bayesian Information Criterion

171 (BIC) to choose the most parsimonious model. number of spider webs of each type (Fig. 1) in each exclosure and each paired control plot. We

174 then computed the $\log$ response ratio $\mathrm{L}$ for the abundance of each web type where

$175 \mathrm{~L}=\ln \left(\mathrm{N}_{\text {no deer }} / \mathrm{N}_{\text {deer }}\right)$. When $\mathrm{N}_{\text {no deer }}=\mathrm{N}_{\text {deer }}, \mathrm{L}=0$. Negative values of $\mathrm{L}$ indicate more spider

176 webs in plots where deer are present, while positive values indicate more webs in plots where 
177 deer are excluded. A 95\% confidence interval was calculated for each spider web type $\mathrm{L}$ to

178 determine if it differed from zero.

179 We combined values for $\mathrm{L}$ from all webs using techniques developed for meta-analysis.

180 Data from each web type were combined to create a mean log response ratio as an effect size,

181 following the procedures outlined in Hedges et al. (1999). To account for among-web type

182 variation in effect sizes, we combined effect sizes from each web type to calculate the mean

183 effect size, or overall effect. The effect size of each spider web type was first weighted by its

184 inverse sampling variance plus a constant, $\mathrm{v}_{\theta}$. The computation of $\mathrm{v}_{\theta}$ is derived from

185 homogeneity analysis and represents variability across population effects (Hedges et al. 1999).

186 To determine if the mean effect size differed from zero, we constructed $95 \%$ confidence

187 intervals. We considered the effects of deer on spider web abundance to be statistically

188 significant if $95 \%$ confidence intervals did not include zero.

189 We counted the number of prey items captured on each sticky trap at our Northern

190 Highlands site, and computed the mean number of prey items per plot. We also measured the

191 length of each prey item to obtain a mean prey size. We calculated log response ratios of prey

192 abundance and size, and computed $95 \%$ confidence intervals using the same procedure as above.

193 We performed an ordination to examine the differences in spider assemblages between

194 exclosures and controls. We created a web type $\times$ plot matrix, with 7 web types and 20 control-

195 exclosure plots. Each element of this matrix contained the number of webs tallied. We used

196 PRIMER 6 (Clarke and Gorley 2006) to create a dissimilarity matrix using the Bray-Curtis

197 measure of ecological distance. This non-Euclidian dissimilarity scales from 0 to 100 . Web type

198 abundance data were square root transformed prior to the creation of the dissimilarity matrix.

199 This transformation had the effect of down-weighting the most abundant web types, which 
200 slightly increases the distance between data points in ordination space for easier interpretation

201 (Clarke and Warwick 2001). This had no measurable effect on subsequent analyses. We used

202 non-metric multidimensional scaling (NMDS) to project the ecological distances among plots,

203 based on 100 random starting configurations and applied a stopping rule when Kruskal stress

204 reached 0.005 (Clarke and Gorley 2006). We used the vegan package in R (Oksanen et al. 2015)

205 to further analyze multivariate patterns, based on an untransformed Bray-Curtis dissimilarity

206 matrix of plot composition. We used the adonis function to perform a permutational multivariate

207 analysis of variance (PERMANOVA). This was based on 999 permutations to test for significant

208 differences in spider composition due to deer browsing (exclosure and control plots), and

209 geographic location (Northern Highlands and Allegheny Plateau plots). This was followed with

210 the permutest.betadisper function to test for homogeneity of dispersions among groups. This

211 multivariate dispersion analysis tests whether the average within-group dispersion is equivalent

212 among groups (Anderson and Walsh 2013). This was also based on 999 permutations to test for

213 significant differences in multivariate dispersion due to deer browsing (exclosure and control

214 plots), and geographic location (Northern Highlands and Allegheny Plateau plots).

215

216 RESULTS

217 We tallied 1567 spider webs (Table 1). There were about twice as many spider webs in

218 plots without deer compared to plots with deer $(101.9 \pm 10.5 \mathrm{SE}$ vs. $54.8 \pm 6.0 \mathrm{SE}$; df $=9$; paired

$219 \mathrm{t}=5.16 ; \mathrm{P}<0.001)$.

220 In plots without deer, web-building spiders had more structures upon which to anchor

221 their webs. Web-scaffold availability $0.5 \mathrm{~m}$ above the forest floor was over seven times greater

222 in plots without deer $(72.3 \pm 11.9 \mathrm{SE}$ vs. $10.2 \pm 3.2 \mathrm{SE})$, and over twelve times greater $1.0 \mathrm{~m}$ 
223 above the ground ( $39.7 \pm 12.3 \mathrm{SE}$ vs. $3.2 \pm 1.9 \mathrm{SE} ;$ Fig. 2$)$. Web-scaffold availability did not

224 differ significantly between Northern Highlands and Allegheny Plateau plots at $0.5 \mathrm{~m}(\mathrm{df}=18 ; \mathrm{t}$

$225=0.38 ; \mathrm{P}=0.70)$, or $1.0 \mathrm{~m}(\mathrm{df}=18 ; \mathrm{t}=0.97 ; \mathrm{P}=0.34)$. The most parsimonious model

226 predicting the abundance of spider webs had a single predictor variable: WSAI at $1.0 \mathrm{~m}$ (Fig. 3).

227 The WSAI at $0.5 \mathrm{~m}$ was not a significant predictor of spider web abundance when the WSAI at

2281.0 is taken into account $\left(\mathrm{n}=20 ; \mathrm{r}^{2}=0.10 ; \mathrm{P}=0.17\right)$.

229

In the Northern Highlands region, total prey availability was significantly higher in plots

230 without deer $(886.8 \pm 160.8 \mathrm{SE})$ compared to plots with deer $(330.0 \pm 53.8 \mathrm{SE}$; effect size $=-$

$2310.98 \pm 0.13 ; 95 \% \mathrm{CI}=-1.48,-0.65)$. Mean prey size did not differ between plots without deer

$232(2.80 \pm 0.16 \mathrm{~mm} \mathrm{SE})$ and plots with deer $(2.61 \pm 0.10 \mathrm{~mm}$ SE; effect size $=0.08 \pm 0.04 ; 95 \% \mathrm{CI}$

$233=-0.11,0.25)$

Analysis of log response ratios revealed that, with the exception of funnel web-builders,

235 all spider web types were significantly more abundant in plots without deer (Fig. 1, 4). Vertical

236 and horizontal orb weavers accounted for the largest responses. Both of these groups were nearly

237 three times more abundant in plots without deer. When response ratios were combined for all

238 web types, spider webs were clearly more abundant in deer-free plots (Fig. 4).

239

A 3-dimensional NMDS solution (Kruskal stress $=0.07)$ provided a better fit than a 2-

240 dimensional solution (Kruskal stress $=0.15$ ). While NMDS ordination did not appear to reveal

241 strong differences in the structure of web-building spider guilds between plots with and without

242 deer (Fig. 5), differences were statistically significant (PERMANOVA $\mathrm{R}^{2}=0.20 ; \mathrm{P}=0.002$ ).

243 There were also significant differences in web-building spider guild composition between the

244 Northern Highlands and Allegheny Plateau regions (PERMANOVA R ${ }^{2}=0.13 ; \mathrm{P}=0.014$ ).

245 Dispersion analysis indicated within-group dispersion did not differ significantly between plots 
246 with and without deer $(\mathrm{df}=1,18 ; \mathrm{F}=0.14 ; \mathrm{P}=0.73)$ or between the Northern Highlands and

247 Allegheny Plateau regions $(\mathrm{df}=1,18 ; \mathrm{F}=2.25 ; \mathrm{P}=0.16)$.

248

249

DISCUSSION

250

251

In both the Allegheny Plateau and Northern Highlands regions, web-building spiders

252 differed in abundance and composition between areas with and without deer. With deer excluded, plots had about seven times the number of anchoring points for webs, and twice as many web-building spiders. Nearly all web structure types increased in abundance when deer were excluded; only funnel weavers were not strongly affected. Prey availability was higher in plots with deer, where the abundance of spiders was much lower. Miyashita et al. (2004) did not find a relationship between prey abundance and deer exclusion. This probably reflects a difference in sampling intensity. Our prey sticky traps were 7.5 times larger and deployed nearly 4 times longer. Our findings suggest that deer, not prey availability, account for differences in web-building spider assemblages between plots with and without deer. When deer are present, web-building spider abundance appears limited by vegetation structure and the availability of

262 locations to anchor webs (Rypstra 1983; Miyashita et al. 2004; Takada et al. 2008). In the

263 absence of deer, anchoring locations are abundant. In these circumstances, web-building spider 264 abundance will often be limited by prey availability (Rypstra 1983; Wise 1993). The impact of 265 deer on vegetation, spiders, and prey availability is likely sequential. Deer overabundance and 266 subsequent herbivory decreases vegetation complexity. Deer, therefore, lower the availability of 267 web-anchoring locations for spiders reducing spider abundance and predation. This, in turn, 268 increases prey availability in areas with high deer abundance. Following this logic, if spiders 
269 were selecting habitat based on prey availability, higher spider abundance would be expected in 270 areas with deer present.

271 There is a plausible alternative explanation for the increase in prey density. It could

272 merely reflect additional space use by prey in the absence of structural impediments created by

273 vegetation. By this explanation, deer reduce vegetation structure, allowing for more invertebrates

274 to fly unimpeded through plots. This results in larger numbers of prey being captured by sticky

275 traps. Reduced capture and predation of prey by spiders does not need to be invoked to account

276 for the increase in invertebrate prey. To determine the relative contributions of spider predation

277 and vegetation structure on prey availability, a future study should manipulate both factors in a 2

$278 \times 2$ factorial experiment.

279 A visual inspection of sample plots in spider assemblage space (Fig. 5) suggests modest

280 effects of deer on community structure, despite statistical significance. The absence of strong

281 clustering of sample plots into those with and without deer probably reflects the effects of deer

282 on nearly all web structures (Fig. 4). In plots with deer, the decline in spider web abundance is

283 more or less evenly spread across all web types. As a result, community structure remains little

284 changed as a more or less random loss of individual webs as the capacity of the habitat to support

285 web-building spiders that rely on complex vegetation structure declines. Only the small, dense

286 webs of funnel-weavers were unaffected. Funnel weavers tend to construct their webs at ground

287 level, so these spiders are the least likely to be affected by changes in vegetation architecture.

288 Other researchers report that the abundance and/or richness of web-building spiders

289 increased in forest areas where deer were experimentally excluded (Miyashita et al. 2004;

290 Suominen and Danell 2006; Takada et al. 2008). Under the closed forest canopies of our study

291 region, the density of shrubs and tree saplings is often low, owing to low light levels, recalcitrant 
292 understory layers that inhibit woody plant growth, and feeding by deer (Horsley et al. 2003; Sage

293 et al. 2003; Royo and Carson 2006). Hence there are few opportunities for web-building spiders

294 to anchor their webs. Recruitment of web-building spiders might therefore become increasingly

295 disturbance-dependent because large canopy disturbances increase the abundance and density of

296 woody vegetation in the understory. These episodic disturbances could provide key web building

297 substrates lacking in intact forest in areas where deer are abundant. While episodic recruitment is

298 a common feature of marine systems and disturbance-dependent plant populations, it is possible

299 that the widespread overabundance of deer have created conditions in which terrestrial predatory

300 arthropods may develop this same recruitment pattern.

301 In their review of the effects of deer on ecosystems, Rooney and Waller (2003)

302 differentiated between indirect effects due to modified food web interactions, and indirect effects

303 arising from habitat modification. In this study, we can attribute changes in the distribution and

304 abundance of web-building spiders (except funnel web builders) to habitat modification. We

305 believe causality may occur via multiple pathways. Reductions in the density of spider webs

306 probably contributed at least in part to the rise in arthropod prey we observed. In other words,

307 habitat modification can lead to modified food web interactions. The distinction between habitat

308 modification and modified food web interactions should not be viewed as a strict dichotomy. The

309 linkages from deer to vegetation are trophic; deer reduce the density of saplings (Begley-Miller

310 et al. 2014) that provide web anchoring points. This structural change altered the abundance of

311 web-building spiders at the third or fourth trophic level (depending on prey), which may have

312 increased the abundance of arthropod prey at the second or third trophic level. Nuttle et al.

313 (2011) introduced the concept of a trophic ricochet to describe a top-down effect that altered

314 plant communities, but did not terminate at the lowest trophic level. Instead, it was transformed 
315 to a bottom-up effect that persisted for several decades. In this study, we observe a different type

316 of trophic ricochet: a top-down effect of deer on vegetation structure that indirectly affected

317 organisms at multiple trophic levels. Deer directly reduced habitat quality and indirectly reduced

318 the abundance of predators, albeit arthropod predators that do not feed on deer, which in turn

319 apparently resulted in an increase in arthropod prey. Trophic ricochets may be a widespread

320 response when dominant species, keystone species, or ecosystem engineers modify the habitats.

321

322

323

324

325

326

327

328

329

330

331

332

333

334 335 336

\section{CONCLUSION}

Deer browsing has profound implications for web-building spiders in the forest understory layer. Of the families of spiders we studied, only the funnel web-builders appeared unaffected. Deer greatly modified habitat structure, reducing opportunities for spiders to anchor webs. This reduced the density of spider webs, and in turn led to a 2.7-fold increase in spider prey abundance. Thus, deer herbivory indirectly altered arthropod predator-prey interactions throughout the forest understory. These changes are probably not unique to our study sites, but instead reflect changes throughout both the Allegheny Plateau and Northern Highland regions. Deer populations have increased in both regions since the 1970s (Ripple et al. 2010). The effect sizes we observed in our study are perhaps larger than occur throughout the region, because exclosures create the artificial condition of vegetation development in the absence of deer. However, we do not know if web-building spider abundance responds to thresholds in deer abundance, or whether such responses are linear. Studies that take advantage of natural gradients 
337 in deer abundance might provide better estimates of contemporary effect sizes, although such

338 correlative studies have limitations.

339

340 ACKNOWLEDGEMENTS

341

342 We thank John Wenzel, John Dzemyan, Rhett Rautsaw, Maureen McGeean Lake, and Tim

343 Hanson for helping make this project possible. We also thank Dairymen's Inc. for access to their

344 property. Volker Bahn performed the dispersion analysis in R. Chris Habeck, David Wise,

345 Michael J. Singer, and an anonymous reviewer provided valuable suggestions for improving an

346 early draft of this manuscript. 
347

348

349

350 351 557-574. doi: 10.1890/12-2010.1

352

353

354

355

356

357

358

359

360

361

362

363

364

365

366

367

368 369

\section{LITERATURE CITED} Angeles, CA.

$10.1656 / 045.022 .0412$

Anderson MJ, Walsh DCI. 2013. PERMANOVA, ANOSIM, and the Mantel test in the face of heterogeneous dispersions: What null hypotheses are you testing? Ecological Monographs 83:

Begley-Miller DR, Hipp AL, Brown BH, Hahn M, Rooney TP. 2014. White-tailed deer are a biotic filter during community assembly, reducing species and phylogenetic diversity. AoB Plants. 6: plu030. doi: 10.1093/aobpla/plu030

Bradley RA. 2013. Common Spiders of North America. University of California Press, Los

Bressette JW, Beck H, Beauchamp VB. 2012. Beyond the browse line: complex cascade effects mediated by white-tailed deer. Oikos. 121: 1749-1760. doi: 10.1111/j.1600-0706.2011.20305.x

Chips MJ, Yerger EH, Hervanek A, Nuttle T, Royo AA, Pruitt JN, McGlynn TP, Riggall CL, Carson WP. 2015. The indirect impact of long-term overbrowsing on insects in the Allegheny National Forest region of Pennsylvania. Northeastern Naturalist 22 : 782-797. doi:

Clarke KR, Gorley RN. 2006. PRIMER v6: User manual/tutorial. PRIMER-E, Plymouth, U.K. 
370 Clarke KR, Warwick RM. 2001. Change in marine communities: an approach to statistical

371 analysis and interpretation, $2^{\text {nd }}$ edition. PRIMER-E: Plymouth.

372

373 Côté SD, Rooney TP, Tremblay JP, Dussault C, Waller DM 2004. Ecological impacts of deer

374 overabundance. Ann. Rev. Ecol. Evol. Syst. 35: 113-147. doi:

375 10.1146/annurev.ecolsys.35.021103.105725

376

377 Crête. M. 1999. The distribution of deer biomass in North America supports the hypothesis of 378 exploitation ecosystems. Ecology Letters 2: 223-227. doi: 10.1046/j.1461-0248.1999.00076.x

380 Gómez J, Lohmiller J, Joern A. 2016. Importance of vegetation structure to the assembly of an 381 aerial web-building spider community in North American open grassland. Journal of

382 Arachnology 44: 28-35. doi: http://dx.doi.org/10.1636/P14-58.1

383

384 Habeck CW, Schultz AK. 2015. Community-level impacts of white-tailed deer on understorey 385 plants in North American forests: a meta-analysis. AoB Plants 7: plv119.

386 doi:10.1093/aobpla/plv119

387

388 Hamilton DJ. 2000. Direct and indirect effects of predation by common eiders and abiotic 389 disturbance in an intertidal community. Ecological Monographs 70: 21-43. doi: 10.1890/0012-

390 9615(2000)070[0021:DAIEOP] 2.0

391 
392 Hedges LV, Gurevitch J, Curtis PS. 1999. The meta-analysis of response ratios in experimental 393 ecology. Ecology 80: 1150-1156. doi:10.1890/0012-9658(1999)080[1150:TMAORR]2.0.CO;2 394

395 Holt CA, Fuller RJ, Dolman PM. 2011. Breeding and post-breeding responses of woodland birds 396 to modification of habitat structure by deer. Biological Conservation 144: 2151-2162.

397 doi:10.1016/j.biocon.2011.05.004

398

399 Horsley S, Stout S, DeCalesta D. 2003. White-tailed deer impact on the vegetation dynamics of a 400 northern hardwood forest. Ecological Applications 13(1):98White doi: 10.1890/1051401 0761(2003)013[0098:WTDIOT]2.0.CO;2 402

Jones CG, Lawton JH, Shachak M. 1994. Organisms as ecosystem engineers. Oikos. 69: 373404 386. doi: $10.2307 / 3545850$

405

Leopold A, Sowls LK, Spencer DL. 1947. A survey of over-populated deer ranges in the United 407 States. Journal of Wildlife Management 11:162 Lore doi: 10.2307/3795561

408

McShea WJ. 2000. The influence of acorn crops on annual variation in rodent and bird populations. Ecology. 81: 228-238. doi: 10.1890/0012-9658(2000)081[0228:TIOACO]2.0.CO;2

411

412 McShea WJ, Rappole JH. 2000. Managing the abundance and diversity of breeding bird 413 populations through manipulation of deer populations. Conservation Biology 14: 1161-1170. doi: $414 \quad 10.1046 / \mathrm{j} .1523-1739.2000 .99210 . x$ 
415

416 Menge BA. 1995. Indirect effects in marine rocky intertidal interaction webs: patterns and

417 importance. Ecological Monographs 65: 21-74. doi: 10.2307/2937158

418

419 Menge BA. 1997. Detection of direct versus indirect effects: were experiments long enough?

420 American Naturalist 149: 801-823. doi: 10.1086/286025

421

422 Miyashita T, Takada M, Shimazaki, A. 2004. Indirect effects of herbivory by deer reduce

423 abundance and species richness of web spiders. Ecoscience 11: 74-79. doi:

$424 \quad 10.1080 / 11956860.2004 .11682811$

425

426 Nuttle T, Yerger EH, Stoleson SH, Ristau TE. 2011. Legacy of top-down herbivore pressure

427 ricochets back up multiple trophic levels in forest canopies over 30 years. Ecosphere 2 : 397-409.

428 doi: 10.1890/ES10-00108.1

429

430 Oksanen J, Blanchet FG, Kindt R, Legendre P, Minchin PR, O'Hara RB, Simpson GL, Solymos

431 P, M. Stevens HH, Wagner H. 2015. vegan: Community Ecology Package. R package version

432 2.2-1. http://CRAN.R-project.org/package=vegan

433

434 Parsons EWR, Maron JL, Martin TE. 2013. Elk herbivory alters small mammal assemblages in

435 high-elevation drainages. Journal of Animal Ecology. 82: 459-467. doi: 10.1111/1365-

$436 \quad 2656.12009$

437 
438 Pringle RM. 2008. Elephants as agents of habitat creation for small vertebrates at the patch scale.

439 Ecology 89: 26-33. doi: 10.1890/07-0776.1

440

441

442 Ripple WJ, Rooney TP, Beschta RL. 2010. Large predators, deer, and trophic cascades in the 443 mid-latitudes. Pages 141-161 in J Terborgh and JA Estes, eds. Trophic Cascades: Predators, 444 Prey, and the Changing Dynamics of Nature. Island Press, Washington DC 445

Rooney TP. 2001. Deer impacts on forest ecosystems: A North American perspective. Forestry 447 74: 201-208. doi: 10.1093/forestry/74.3.201

448

449 Rooney TP. 2009. High white-tailed deer densities benefit graminoids and contribute to biotic 450 homogenization of forest ground-layer vegetation. Plant Ecology 202: 103-111. doi:

$451 \quad 10.1007 / \mathrm{s} 11258-008-9489-8$

452

453

Rooney TP, Waller DM. 2003. Direct and indirect effects of white-tailed deer in forest 454 ecosystems. Forest Ecology and Management 181:165t gro doi: 10.1016/S0378-1127(03)00130$455 \quad 0$ 456

457 Royo AA, Carson WP. 2006. On the formation of dense understory layers in forests worldwide: 458 consequences and implications for forest dynamics, biodiversity, and succession. Canadian 459 Journal of Forest Research 36:1345-1362. doi: 10.1139/x06-025 460 
461 Rypstra AL. 1983. The importance of food and space in limiting web-spider densities; a test

462 using field enclosures. Oecologia 59: 312-316. doi: 10.1007/BF00378855

463

464 Sage RW, Porter WF, Underwood HB. 2003. Windows of opportunity: white-tailed deer and the 465 dynamics of northern hardwood forests of the northeastern US. Journal of Nature Conservation 466 10: 213-220. doi: 10.1016/S0304-3800(03)00220-5

467

468 Sakai M, Natuhara Y, Imanishi A, Imai K, Kato M. 2012. Indirect effects of excessive deer 469 browsing through understory vegetation on stream insect assemblages. Population Ecology 54: 65-74. doi: 10.1007/s10144-011-0278-1

471

472 Stewart AJA. 2001. The impact of deer on lowland woodland invertebrates: a review of the 473 evidence and priorities for future research. Forestry 74: 259-70. doi: 10.1093/forestry/74.3.259 474

475 Suominen O, Danell K. 2006. Pages 383-412 in K Danell R Bergström, P Duncan, J Pastor, eds. 476 Large Herbivore Ecology, Ecosystem Dynamics, and Conservation. Cambridge University Press, 477 Cambridge.

478

479 Takada M, Baba YG, Yanagi Y, Terada S, Miyashita T. 2008. Contrasting responses of web480 building spiders to deer browsing among habitats and feeding guilds. Environmental Entomology 481 37: 938-946. doi: 10.1603/0046-225X(2008)37[938:CROWST]2.0.CO;2 482 
483 Takatsuki S. 2009. Effects of sika deer on vegetation in Japan: a review. Biological Conservation 484 142: 1922-1929. doi: 10.1016/j.biocon.2009.02.011

485

486 Uetz GW. 1991. Habitat structure and spider foraging. Pages 325-348 in Bell SS, McCoy ED, 487 Mushinksy, HR, eds. Habitat Structure: The Physical Arrangement of Objects in Space.

488 Chapman and Hall, London.

489

490 Vourc'h G, Martin JL, Duncan P, Escarré J, Clausen TP. 2001. Defensive adaptation of Thuja 491 plicata to ungulate browsing: a comparative study between mainland and island populations. 492 Oecologia 126-buildin doi: 10.1007/s004420000491

493

494 Warren RJ. 1997. The challenge of deer overabundance in the 21 st century. Wildlife Society 495 Bulletin 25: 213-214.

496

497 Whitney GG. 1990. The history and status of the hemlock-hardwood forests of the Allegheny 498 Plateau. Journal of Ecology 78: 443-458. doi: 10.2307/2261123

499

500 Wise DH. 1993. Spiders in Ecological Webs. New York, NY: Cambridge University Press, 501 Cambridge.

502

503 Wootton JT. 1994. The nature and consequences of indirect effects in ecological communities.

504 Annual Review of Ecology and Systematics 25: 443-466. doi:

505 10.1146/annurev.es.25.110194.002303 
506 Table 1. Web type, putative family (based on Bradley 2013), number of individual webs

507 identified in exclosure (deer free) and control (browsed) plots.

508

\begin{tabular}{llll} 
Web Type & Family & Exclosure & Control \\
\hline \hline & & & \\
Funnel weavers & Agelenidae & 122 & 136 \\
Sheet weavers & Linyphiidae & 345 & 187 \\
Mesh weavers & Dictynidae & 77 & 30 \\
Reduced orb or line weavers & Uloboridae & 21 & 5 \\
Vertical orb weavers & Aranaeidae & 133 & 45 \\
Tangle web weavers & Theridiidae & 190 & 97 \\
Horizontal orb weavers & Tetragnathidae & 131 & 48
\end{tabular}


511

512 Fig. 1. Web structures (a) funnel web (Agelenidae), (b) sheet web (Linyphiidae), (c) mesh web

513 (Dictynidae), (d) reduced orb web (Uloboridae), (e) vertical orb web (Aranaeidae), (f) tangle web

514 (Theridiidae), (g) horizontal orb web (Tetragnathidae). Line drawings by E.J. Roberson.

515

516 Fig. 2. Web scaffold availability index (WSAI) in control and exclosure plots $0.5 \mathrm{~m}(\mathrm{df}=18 ; \mathrm{t}=$

517 5.58; $\mathrm{P}<0.001)$ and $1.0 \mathrm{~m}(\mathrm{df}=18 ; \mathrm{t}=7.37 ; \mathrm{P}<0.001)$ above the ground. Horizontal lines

518 indicate mean values. WSAI was natural log transformed prior to statistical analysis.

519

520 Fig. 3. The abundance of spider webs as a function of web scaffold availability index (WSAI) at

$1.0 \mathrm{~m}$. Abundance $=1.12 \mathrm{WSAI}+28.2\left(\mathrm{df}=1,18 ; \mathrm{F}=9.07 ; \mathrm{r}^{2}=0.335 ; \mathrm{P}=0.008\right)$.

523 Fig. 4. Log response ratio (ratios of number of webs in exclosure plots compared to paired

524 control plots) and 95\% confidence intervals for all web types. Positive values indicate greater

525 web density in the absence of deer. Confidence intervals that intercept zero indicate no

526 significant difference $(\mathrm{P}>0.05)$.

527

528 Fig. 5. NMDS ordination of each web type found in control (open) and exclosure (solid) plots in 529 the Allegheny Plateau (AP) and Northern Highlands (NH) region. Only the two most variable 530 dimensions of a 3-dimensional solution are shown. 


\section{$532 \quad$ Fig 1}
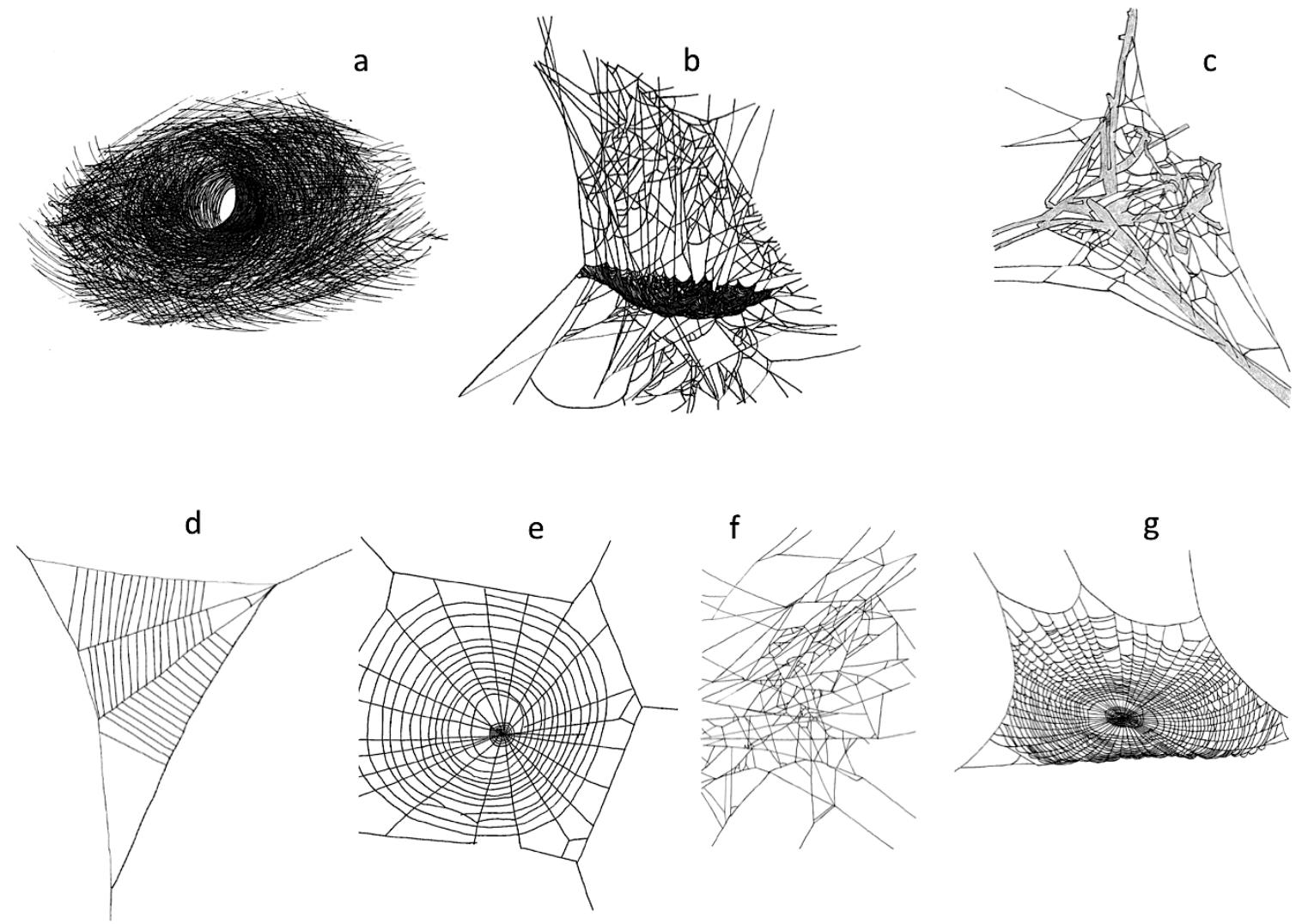

533 
$534 \quad$ Fig 2

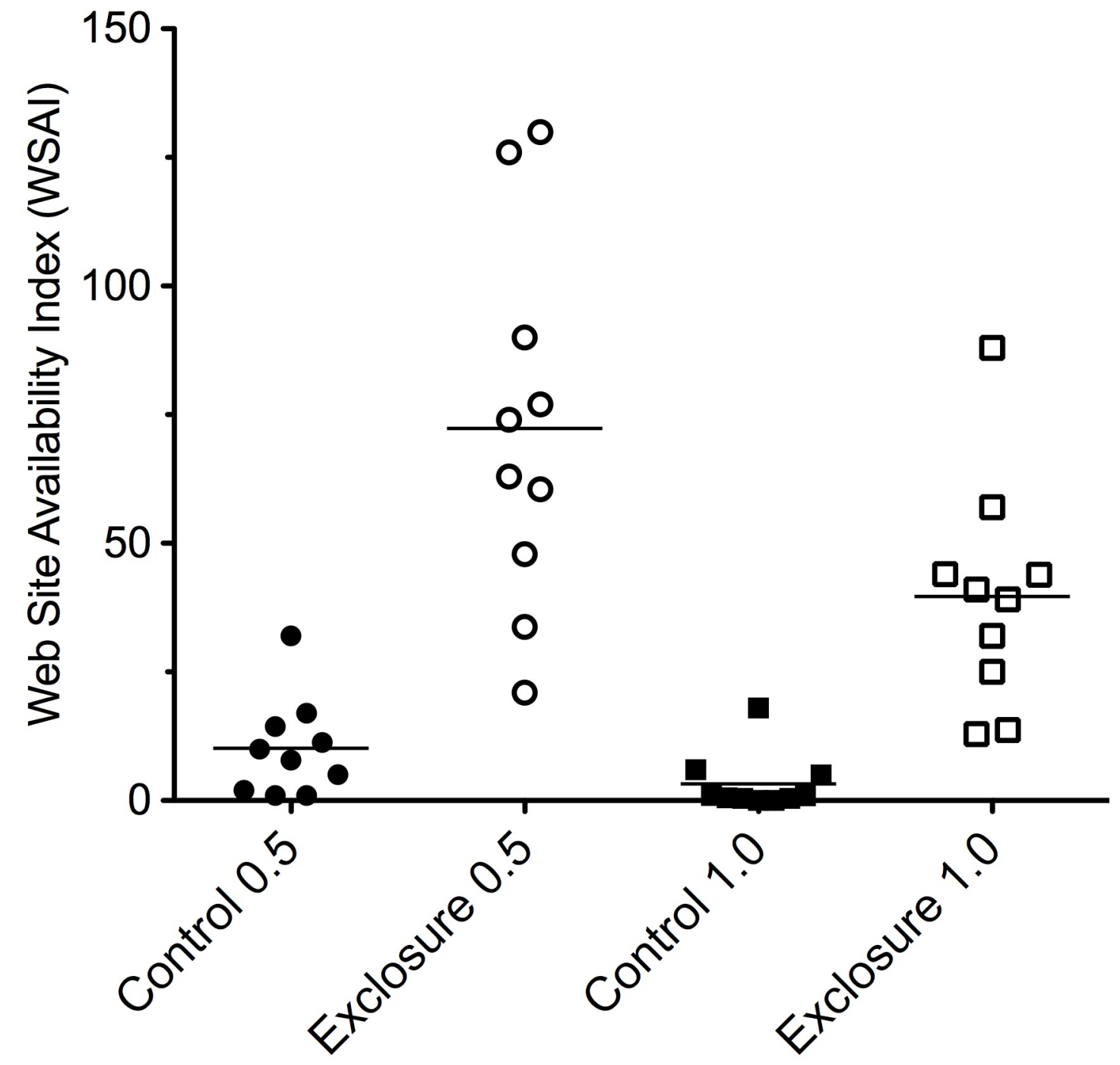

535 
$536 \quad$ Fig 3

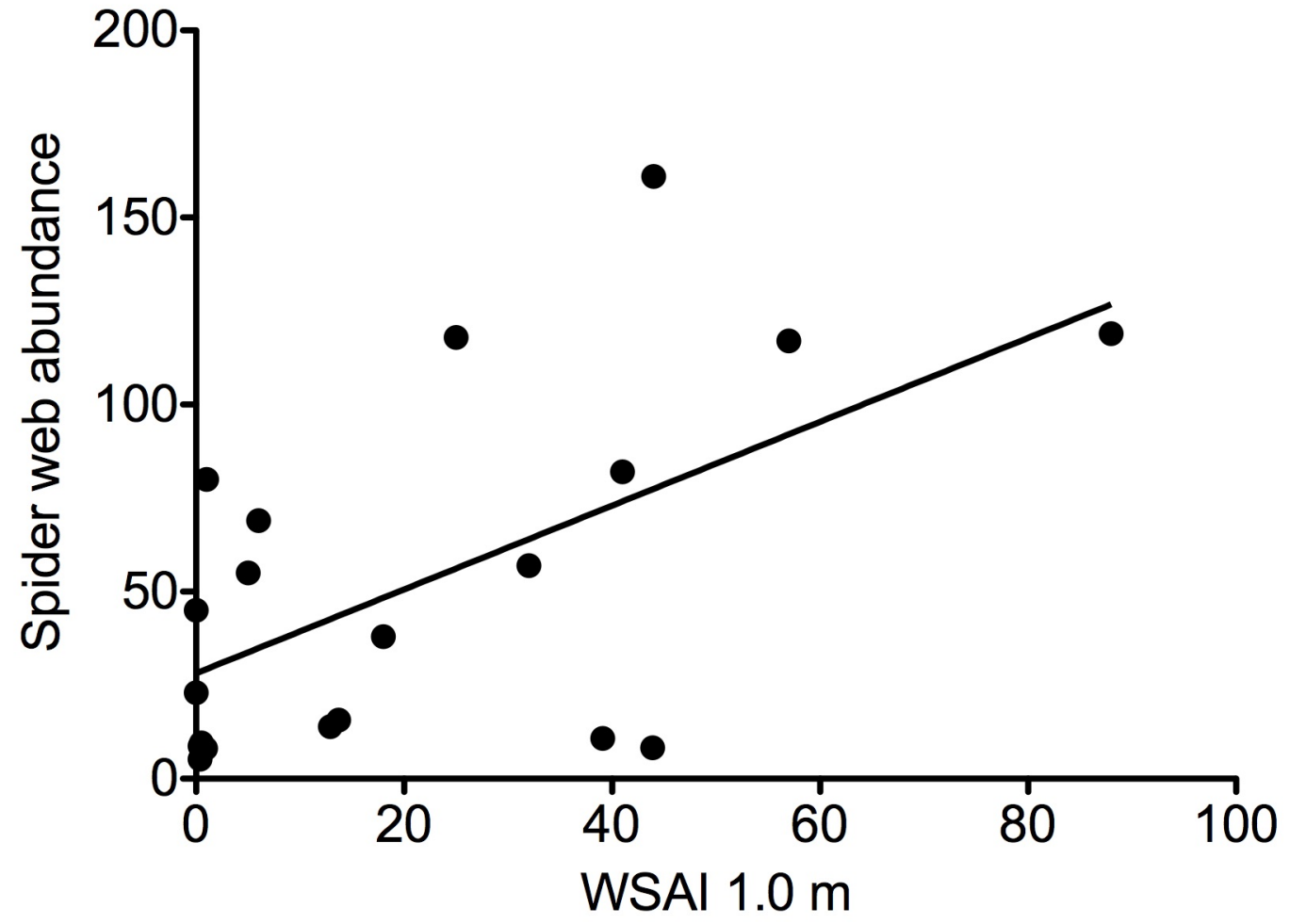

537 
$538 \quad$ Fig 4

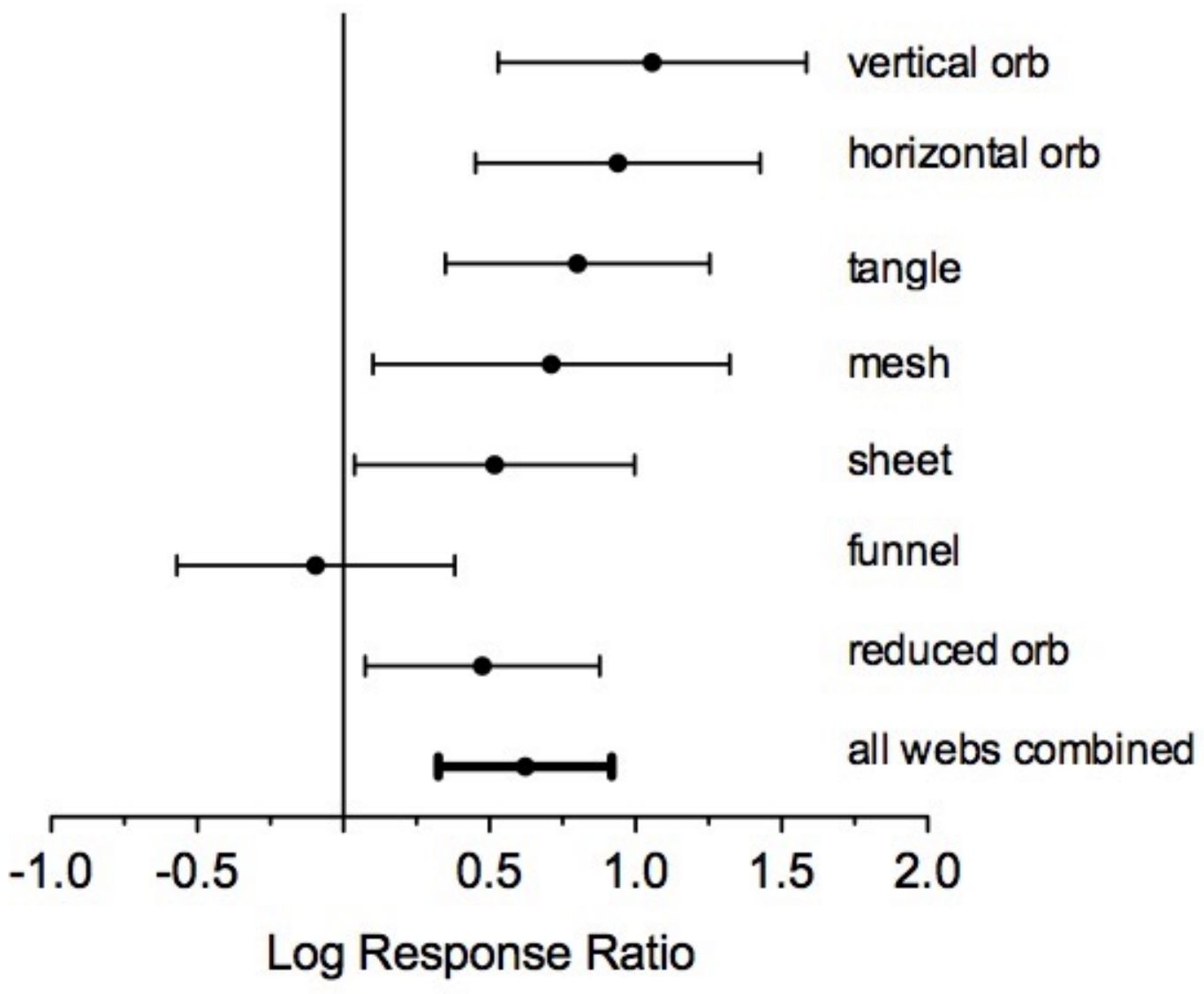

539 
$540 \quad$ Fig 5

\section{$\square$ AP Deer \\ - AP No Deer}

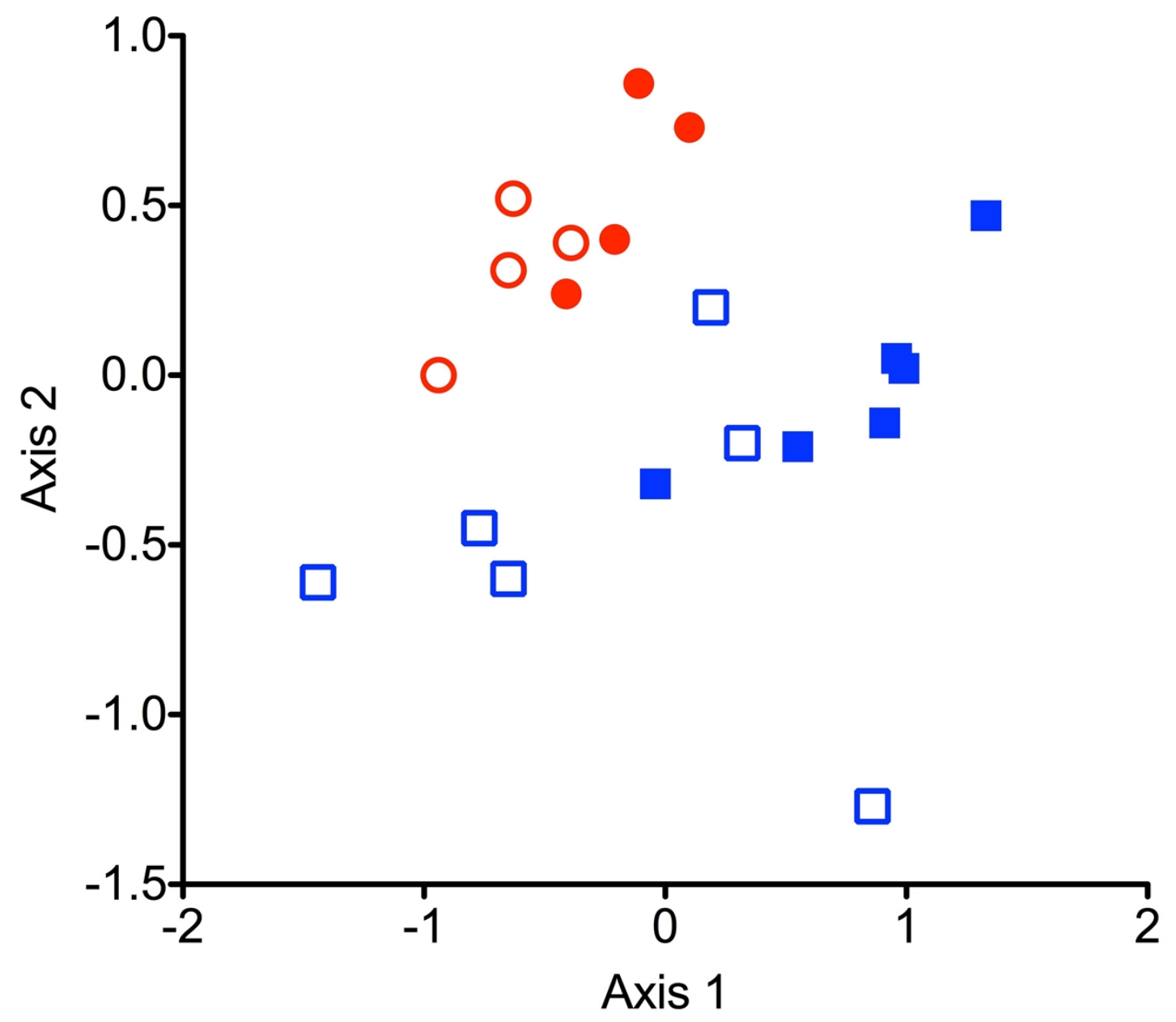

